\title{
Identification and Elimination of the Clinically Relevant Multi-Resistant Environmental Bacteria Ralstonia insidiosa in Primary Cell Culture
}

\author{
Dennis Nurjadi ${ }^{1}$, Sébastien Boutin ${ }^{1}$, Katja Schmidt ${ }^{2}{ }^{\oplus}$, Melinda Ahmels ${ }^{3}$ and Daniel Hasche ${ }^{3, *}$ \\ 1 Department of Infectious Diseases, Medical Microbiology and Hygiene, Heidelberg University Hospital, \\ Im Neuenheimer Feld 324, 69120 Heidelberg, Germany; Dennis.Nurjadi@med.uni-heidelberg.de (D.N.); \\ Sebastien.Boutin@med.uni-heidelberg.de (S.B.) \\ 2 German Cancer Research Center (DKFZ), Division of Microbiological Diagnostics (W440), \\ Im Neuenheimer Feld 280, 69120 Heidelberg, Germany; katja.schmidt@dkfz-heidelberg.de \\ 3 German Cancer Research Center (DKFZ), Division of Viral Transformation Mechanisms (F030), \\ Im Neuenheimer Feld 242, 69120 Heidelberg, Germany; m.ahmels@dkfz-heidelberg.de \\ * Correspondence: d.hasche@dkfz-heidelberg.de; Tel.: +49-622-42-2922
}

Received: 25 September 2020; Accepted: 15 October 2020; Published: 17 October 2020

\begin{abstract}
In times of spreading multidrug-resistant bacteria, species identification and decontamination of cell cultures can be challenging. Here, we describe a mobile cell culture contaminant with "black dot"-like microscopic appearance in newly established irreplaceable hybridoma cell lines and its identification. Using $16 \mathrm{~S}$ rRNA gene sequencing, species-specific PCRs, whole genome sequencing (WGS), and MALDI-TOF mass spectrometry, the contaminant was identified as the ubiquitous environmental and clinically relevant Gram-negative bacterium Ralstonia insidiosa ( $R$. insidiosa), a strong biofilm producer. Further characterizations by transmission electron microscopy (TEM) and biochemical API test were not conclusive. Whole genome sequencing of our $R$. insidiosa isolate revealed numerous drug-resistance determinants. Genome-wide comparison to other Ralstonia species could not unambiguously designate our isolate to R. insidiosa ( $<95 \%$ average nucleotide identity) suggesting a potential novel species or subspecies, closely related to $R$. insidiosa and R. pickettii. After determining the antibiotic susceptibility profile, the hybridoma cell culture was successfully decontaminated with ciprofloxacin without affecting antibody production.
\end{abstract}

Keywords: bacterial contamination; primary cell culture; Ralstonia insidiosa; multidrug resistance

\section{Introduction}

Contamination with bacteria, yeast, fungi, or other cell lines is a ubiquitous danger for cell cultures, despite aseptic work conditions, autoclaved equipment, and sterile media. While many bacterial contaminations are clearly visible, for instance by massive turbidity and color change of the acidified medium, infiltration and cross-contamination by another cell line often remains undetected [1,2] until subjection to authentication, e.g., by short tandem repeat (STR) profiling [3], as required by more and more journals. Contaminations usually result in the loss of the cell line or misinterpretation of experimental data, for instance due to stealing of nutrients and unwanted activation of signaling cascades [4,5]. Intracellular mycoplasma, which affect up to $30 \%$ of cell lines [6] or slow-growing extracellular bacteria that, contrary to the wide-spread opinion, do not cause medium color change and therefore remain unnoticed pose a particular danger. Published case reports are limited, especially regarding the identification of unknown bacterial contaminants, described as "swimming black dots" $[7,8]$. However, many online science forums contain questions and discussions about unidentified contaminations that appear as extracellular black dots propagated via normal cell 
splitting that may even tend to move [9-13]. Many replying experimenters are still of the opinion that (a) bacterial contamination would cause a color change, and that it is therefore debris driven by Brownian motion, or (b) the cells should simply be discarded. Some good sounding ideas like extensive washing, filtration through strainers, or centrifugation are impracticable, since they will not remove all bacteria. Although several antibiotics are available to clean the cells, many bacteria are multidrug-resistant (MDR), especially to the commonly used combination penicillin/streptomycin. Therefore, the use of uncommon antibiotics that have to be determined a priori by sensitivity testing may be indicated. In most cases, especially when cryopreserved backups or commercial vendors are available, such an effort may be beyond the benefits. Nevertheless, in some cases that involve irreplaceable cells derived from primary sources [14] or precious hybridoma clones that were generated in a laborious and time consuming procedure and produce unique antibodies [15], a cleanup of the cells may be worthwhile.

Irrespective of the laboratory setting, antibiotic resistances are spreading worldwide, also in hospitals. Nosocomial infections represent an emerging problem especially in intensive care units where seriously ill, highly vulnerable and often immunocompromised patients are treated. Such infections have been clearly linked to the use of devices as endotracheal intubation, urinary catheters, and central venous catheters [16]. With the percentage of infections with MDR Gram-negative bacteria increasing, treatment options are limited [17]. Strong biofilm producers like Acinetobacter baumannii [18] or Ralstonia species are hard to fight, as they are well-protected against antimicrobials. The bacterial genus Ralstonia includes ubiquitous environmental bacteria known as phytopathogens (R. solanacearum) [19] and are a growing threat in hospitals, e.g., for patients under mechanical ventilation or suffering from cystic fibrosis (R. pickettii, R. insidiosa, and R. mannitolilytica) [20-22]. They can survive under low-nutrient conditions even in laboratory and hospital water supplies. Further, in particular, $R$. insidiosa as a strong biofilm producer facilitates the settlement of other bacteria $[23,24]$.

Here we report the contamination of unique hybridoma clones with an unknown bacterial contaminant and its identification as a MDR strain of the clinically relevant $R$. insidiosa.

\section{Materials and Methods}

\subsection{Hybridoma Culture Conditions and Amplification of Bacterial Contaminant}

Hybridoma cells obtained from a fusion of murine Sp2/0-Ag 14 cells and Mastomys coucha splenocytes [25] were cultured in 6-well plates in RPMI-1640 (Sigma-Aldrich, catalogue no 8758, Munich, Germany) supplemented with $10 \%(v / v)$ heat-inactivated fetal calf serum (FCS; Gibco, Thermo Fisher Scientific, Waltham, MA, USA), 100 units $/ \mathrm{mL}$ penicillin and $100 \mathrm{mg} / \mathrm{mL}$ streptomycin in at $37^{\circ} \mathrm{C}$ and $5 \% \mathrm{CO}_{2}$.

\subsection{Extraction of Bacteria from the Cell Culture and Pure Culture}

Cell culture medium of a contaminated well was transferred without hybridoma cells to a new well and cultured until the medium was turbid. The medium was resuspended to detach bacteria from the bottom and $100 \mu \mathrm{L}$ were centrifuged for $5 \mathrm{~min}$ at $500 \times \mathrm{g}$ and resuspended in $25 \mu \mathrm{L}$ PCR-grade water for PCRs. Additional aliquots were centrifuged, resuspended in Dulbecco's Phosphate Buffered Saline (DPBS; Sigma-Aldrich, catalogue no R8537, Munich, Germany) and subjected to TEM or to bacterial culture on Columbia blood agar plates with sheep blood (Oxoid, Thermo Fisher Diagnostics $\mathrm{GmbH}$ Microbiology, Wesel, Germany). Agar plates were incubated at $37^{\circ} \mathrm{C}$ and $5 \% \mathrm{CO}_{2}$ until bacteria were sub-cultured $48 \mathrm{~h}$ later.

\subsection{Amplification and Sequencing of the Bacterial 16S RNA Gene}

Bacterial $16 \mathrm{~S}$ rRNA gene was partially amplified with the universal bacterial $16 \mathrm{~S}$ rRNA forward primer 27F (5'-AGAGTTTGATCCTGGCTCAG-3') and the reverse primers 1492R (5'-GGTTACCTTGTTACGACTT-3') or 16s907 (5'-CCGTCAATTCMTTTRAGTTT-3') [26,27] using 
$2 \times$ DreamTaq $^{\circledR}$ Polymerase Master Mix (Thermo Fisher Scientific, Waltham, MA, USA):10 $\mu \mathrm{L} 2 \times$ Master Mix, $1 \mu \mathrm{L}$ Primer Mix $(20 \mu \mathrm{M}), 7 \mu \mathrm{L} \mathrm{H}_{2} \mathrm{O}, 2 \mu \mathrm{L}$ sample. Thermal cycling conditions for PCRs were a primary denaturation step at $95^{\circ} \mathrm{C}$ for $3 \mathrm{~min}$, followed by 30 cycles of $30 \mathrm{~s}$ at $95{ }^{\circ} \mathrm{C}, 30 \mathrm{~s}$ at $55{ }^{\circ} \mathrm{C}, 45 \mathrm{~s}$ at $72{ }^{\circ} \mathrm{C}$, and a final extension step of $10 \mathrm{~min}$ at $72{ }^{\circ} \mathrm{C}$. DNA fragments were separated by electrophoresis on a $1.2 \%$ agarose gel, stained and visualized by UV light. PCR products were extracted from agarose gel with QIAquick ${ }^{\circledR}$ Gel Extraction Kit (Qiagen GmbH, Hilden, Germany) and sequenced with 27F primer by Eurofins Genomics Germany GmbH (Ebersberg, Germany).

\subsection{Specific Identification of R. insidiosa by PCR}

Specific identification of $R$. insidiosa was based on PCR with three primer pairs: 1 . Rp-F1 (5'-ATGATCTAGCTTGCTAGATTGAT-3') \& Rp-R1 (5'-ACTGATCGTCGCCTTGGTG-3') for the detection of $R$. pickettii, 2. Rm-F1 (5'-GGGAAAGCTTGCTTTCCTGCC-3') \& Rm-R1 (5'-TCCGGG TATTAACCAGAGCCAT-3') for the detection of R. mannitolilytica and 3. Rp-F1 \& R38R1 (5'-CACA CCTAATATTAGTAAGTGCG-3') for the detection of $R$. insidiosa $[22,28]$ using $2 \times$ DreamTaq $^{\circledR}$ Polymerase Master Mix (Thermo Fisher Scientific, Waltham, MA, USA) and $2 \mu \mathrm{L}$ sample and the thermal scheme described above. DNA fragments were separated by agarose gel electrophoresis, stained and visualized by UV light. $R$. insidiosa is detected with primer combination Rp-F1/R38R1, but also with Rp-F1/Rp-R1, while it is not detectable with Rm-F1/Rm-R1 [28].

\subsection{API Test}

API ${ }^{\circledR} 20$ NE test (BioMérieux Deutschland GmbH, Nürtingen, Germany) was performed according to the manufacturers' protocol based on current microbiology standards. After incubation at $30^{\circ} \mathrm{C}$ for $24 \mathrm{~h}$ and $48 \mathrm{~h}$, the biochemical reactions and bacterial growth were analyzed according to the manual to determine the numerical profile, which allowed identification using the apiweb ${ }^{\mathrm{TM}}$ identification software.

\subsection{Gram Stain}

Gram staining was performed as previously described [29].

\subsection{Light Microscopy}

Pictures of contaminated cell cultures were taken with an EVOS XL Core Imaging System and 20X or $40 \times$ long working distance (LWD) objectives (Life Technologies Corporation, Bothell, WA, USA).

\subsection{Transmission Electron Microscopy (TEM)}

Bacteria were fixed with buffered aldehyde solution (4\% formaldehyde, $2 \%$ glutaraldehyde,

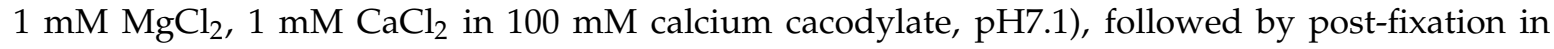
buffered $1 \% \mathrm{OsO}_{4}$, graded dehydration with ethanol and resin-embedding in epoxide (12 g glycid ether, $6.5 \mathrm{~g}$ N,N-dimethylacetamide (NMA), $6.5 \mathrm{~g}$ dodecenylsuccinic anhydride (DDSA), $400 \mathrm{~mL}$ 2,4,6-Tris(dimethylaminomethyl)phenol (DMP30), all from Serva, Heidelberg, Germany). Ultrathin sections at nominal thickness $60 \mathrm{~nm}$ and contrast-stained with lead-citrate and uranyl acetate were observed in a Zeiss EM 910 at 100 kV (Carl Zeiss, Oberkochen, Germany).

\subsection{MALDI-TOF MS and Antibiotic Susceptibility Testing}

For analysis of the species, bacterial pure culture was subjected to MALDI-TOF (matrix-assisted laser desorption-ionization time of flight) mass spectrometry (MS) (Bruker Diagnostics, Germany) as a duplicate and processed by the routine diagnostic laboratory according to current microbiological diagnostic standards. Species identification was performed as duplicates and a score of $>2.0$ was considered reliable to the species level [30]. Antibiotic susceptibility testing was performed using the VITEK ${ }^{\circledR 2}$ (Biomérieux, Nürtingen, Germany) with the AST-N389 panel and interpreted based on the 
EUCAST clinical breakpoints (v10.0) for Pseudomonas spp. There are no breakpoints for bacteria of the genus Ralstonia. Since Ralstonia spp. were once assigned to the genus Pseudomonas [31], clinical breakpoints for Pseudomonas spp. would be the most suitable. MIC (minimal inhibitory concentration) for imipenem and meropenem were confirmed by Etest (Liofilchem, Roseto degli Abruzzi (TE), Italy).

\subsection{Carbapenem Inactivation Assay}

The production of carbapenem hydrolyzing enzyme was detected using a meropenem disk in a carbapenem inactivation assay, as published elsewhere [32]. Briefly, a loopful $(1 \mu \mathrm{L})$ of an overnight culture of Escherichia coli ATCC ${ }^{\circledR} 25922$ (negative control), Verona-integron-metallo-betalactamase-1 (VIM-1) producing Citrobacter amalonaticus KE3510 (positive control) [33] and our R. insidiosa isolate were each suspended in $2 \mathrm{~mL}$ tryptic soy broth (TSB). A meropenem disk (10 $\mu \mathrm{g}$, Sensidisc, BD Diagnostics, Heidelberg, Germany) was added into each bacterial suspension after short vortexing for $10-15 \mathrm{~s}$ and incubated for $4 \mathrm{~h}$ at $37^{\circ} \mathrm{C}$ in ambient air. After this incubation period, each disk was removed from the TSB, excess liquid was removed and placed onto a Mueller-Hinton plate, which was inoculated with the multi-susceptible E. coli ATCC ${ }^{\circledR} 25922$ (0.5 McFarland standard). Reduction in zone of inhibition after $18-24 \mathrm{~h}$ incubation at $37^{\circ} \mathrm{C}$ compared to the meropenem disk incubated with the negative control is an indication of meropenem inactivation.

\subsection{Whole Genome Sequencing and Data Analysis}

Genomic DNA was extracted from overnight bacterial culture using the DNeasy Blood and Tissue Minikit (Qiagen GmbH, Hilden, Germany). Standard genomic library was prepared from the bacterial DNA and sequenced with the Illumina MiSeq platform $(2 \times 300$ bp paired end $)$, as described elsewhere [34]. For quality control, raw sequences were trimmed using Sickle 1.33 (parameters, q > 30; $1>45$ ). Clean reads were assembled with spades 3.13 with the option -careful and -only-assembler [35]. Obtained contigs were curated for length $(>1000 \mathrm{bp})$ and coverage $(>10 \times)$. Sequence was annotated using Prokka 1.14.1 (based on Genetic Code Table 11). Resistance genes were found using Abricate 0.8.13. Briefly, the draft genome was mapped to the database of CARD, NCBI AMRFinderPlus, Resfinder and ARG-ANNOT [36-39] and hits with a minimum identity of $90 \%$ and a minimum coverage of $80 \%$ were considered as AMR genes present in our draft genome. The sequence was uploaded to the NCBI database under Bioproject Accession PRJNA661395.

\subsection{Phylogenetic Tree}

The phylogenetic tree was constructed using the Gubbins algorithm [40] with publicly available complete genomes of Ralstonia spp. from the Refseq database. Briefly, the core genome was calculated using Roary, and contains every gene present in all the species (378 genes). Next, recombination events are detected iteratively using the default setting (-min_snps 3,-converge_method weighted_ robinson_foulds, -iterations 5). The tree was constructed using RAxML. Using the same procedure, a second tree was built using complete and draft genomes of $R$. insidiosa. The core genome was bigger due to close relatedness (3497 genes).

\section{Results}

\subsection{Detection of a Cell Culture Contamination}

Hybridoma clones were generated by fusion of splenocytes from the rodent Mastomys coucha [25] and the murine Sp2/0-Ag 14 cell line, repeatedly screened for the production of specific antibodies and subcloned via limited dilution to ensure monoclonality [15]. Each subcloning required addition of freshly and aseptically isolated feeder splenocytes. After the third and final subcloning, in 11 of the resulting 36 hybridoma lines, tiny black dots that seemed to be mobile could be observed under the microscope (Figure 1A). Although mycoplasma would not be visible, a PCR-based test was performed with a negative result. After larger attached dots without motility appeared and the bottom of the 
plate was covered by a biofilm also visible under the light microscope (Figure 1B). These black dots multiplied and were carried along with usual splitting of the hybridoma cells. To exclude that it was cellular debris, the supernatant of the culture was transferred to a new 6-well plate and cultured under conditions as before. Despite a very low amount of remaining hybridoma cells, the number of these mobile black dots increased. Further, passaging was possible until no hybridoma cells but only the black dots were left, indicating a living contaminant. Indeed, visualization via transmission electron microscope (TEM) showed that these dots were prokaryotes (Figure 1C,D).
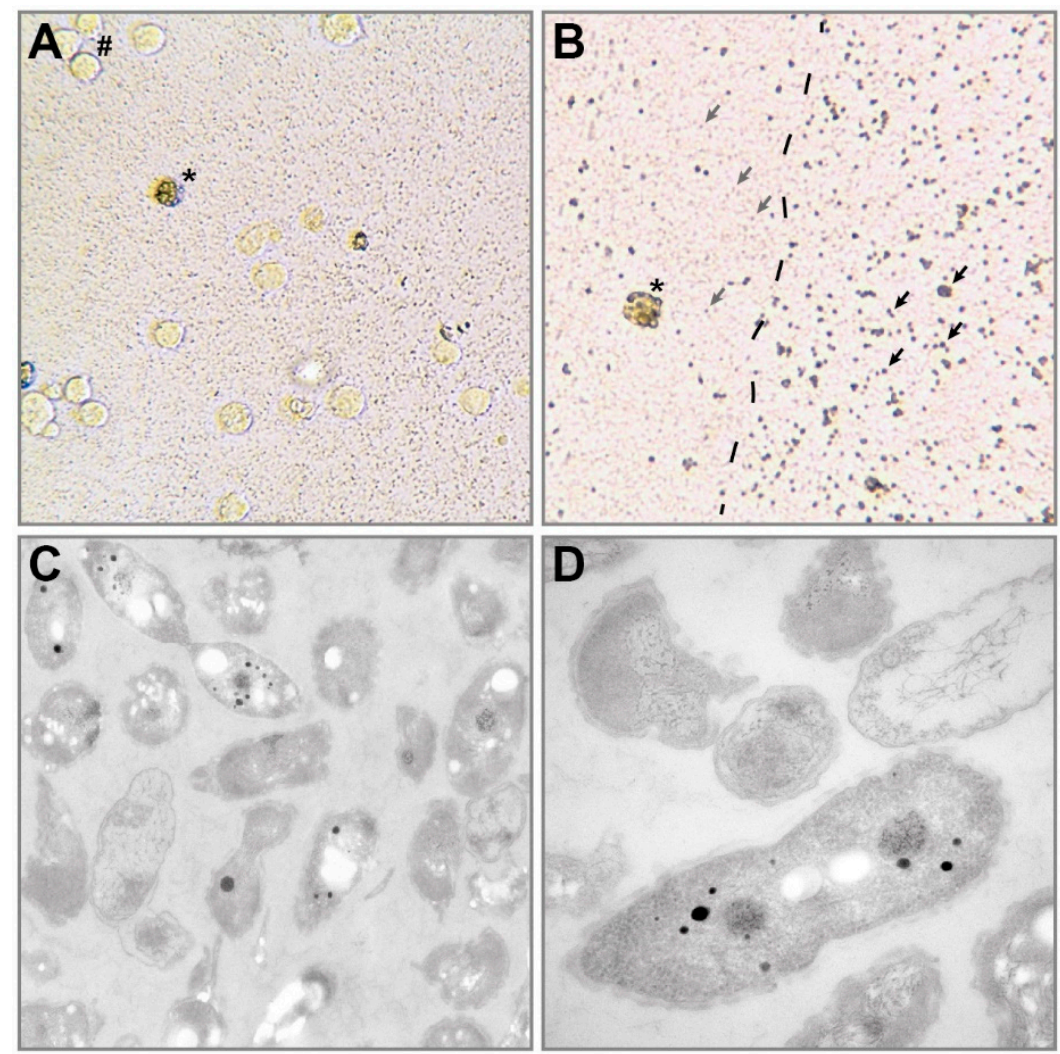

Figure 1. Microscopic observation of the contamination. (A) Contaminated hybridoma culture visualized with a $20 \times$ objective. (B) Propagated contamination visualized with a $40 \times$ objective. Only a few dead hybridoma cells were left, while bacteria produced a biofilm. \#: vital hybridoma cells, * : dead hybridoma cell, grey arrows: swimming bacteria, black arrows: attached bacteria in a biofilm. (C) TEM picture of the bacteria at 20,000 $\times$ magnification. (D) TEM picture of the bacteria at 40,000× magnification.

\subsection{Identification of Bacterial Species}

Although the hybridoma cells were cultured in medium containing penicillin/streptomycin, the contaminant seemed to be a bacterium. Therefore, we ran several approaches to identify the species. We subjected an aliquot of the contaminated culture to PCR for $16 \mathrm{~S}$ rRNA gene amplification via two primer combinations suitable for identification of a broad range of bacteria as previously reported (Figure 2A) [27]. Sequencing of the products revealed 99.6\% (primers 27F \& 1492R) and 98.48\% (primers 27F \& 16s907) sequence homology to $R$. insidiosa. The genus Ralstonia comprises several ubiquitous environmental bacterial species. While some are known as phytopathogens, some members are also associated with hospital infections [41]. Due to their clinical importance, primers have been previously established for the distinction between $R$. pickettii, R. insidiosa, and R. mannitolilytica [22,28]. While amplification with the primer combination Rm-F1/Rm-R1 was negative, primers Rp-F1/Rp-R1 and F1/R38R1 resulted in specific products, which confirmed that our bacterial contaminant was R. insidiosa (Figure 2B), a Gram-negative rod-like bacterium (Figure 2C). The bacterium was cultured on Columbia blood agar and biochemically tested with the API ${ }^{\circledR} 20 \mathrm{NE}$ test system (Figure 2D), which identifies 
bacteria based on their biochemical properties determined in 20 tests (the analytical profile index) [42]. The resulting analytical profile index of 0050555 was compared to the APIWEB ${ }^{\mathrm{TM}}$ database, which indicated $R$. pickettii with a confidence of $56.3 \%$ as it did not contain $R$. insidiosa. Due to this discrepancy in the identification, an additional MALDI-TOF MS analysis was performed and again clearly identified $R$. insidiosa with scores of 2.22 and 2.18 (a score of $>2.0$ is considered a reliable identification to the species level [30]).
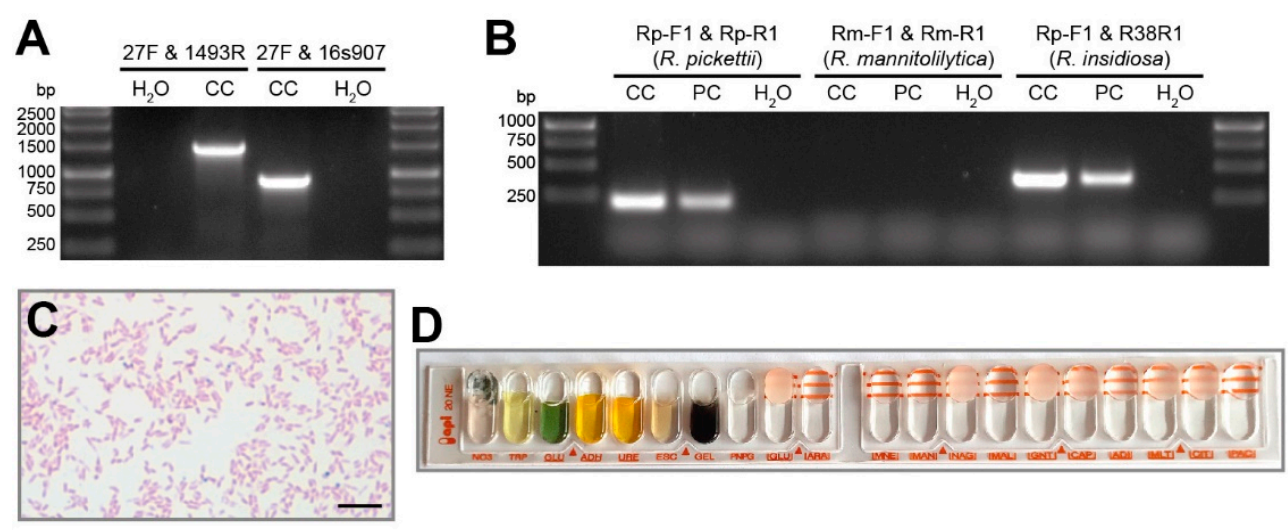

\section{E}

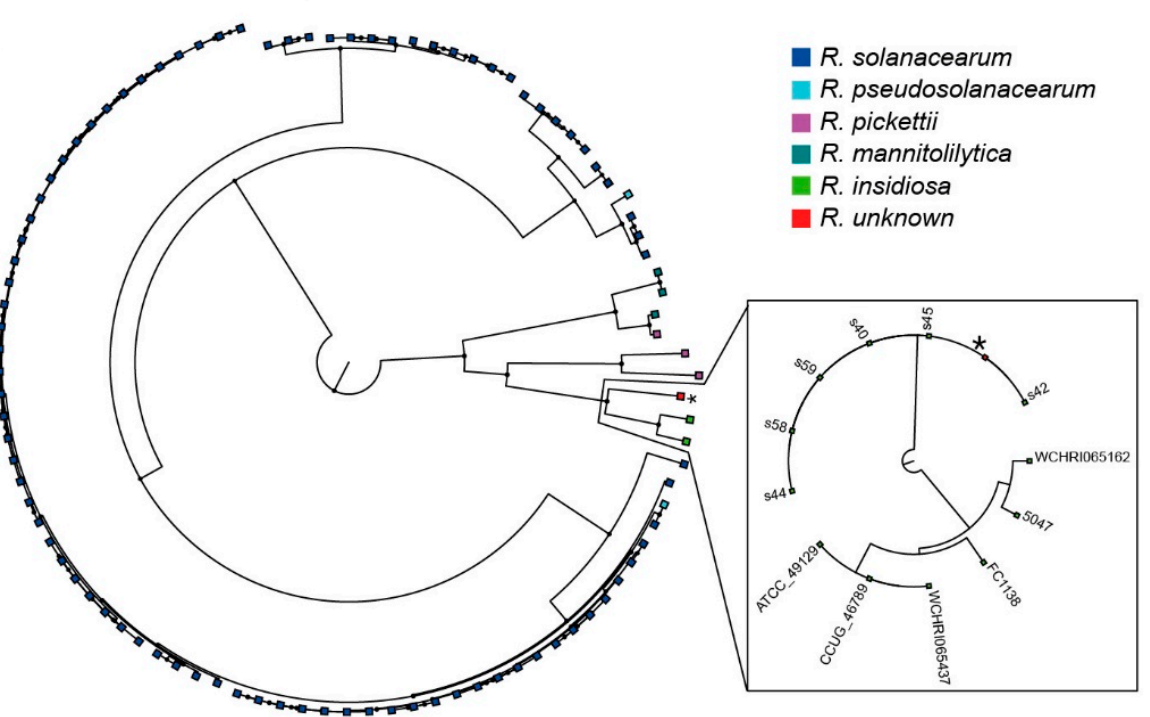

Figure 2. PCR, biochemical and phylogenetic analyses of the contamination. (A) 16S rRNA gene amplification for sequencing with two different primer combinations (CC: sample from contaminated cell culture; $\mathrm{H}_{2} \mathrm{O}$ : water control). (B) Specific identification of Ralstonia species via PCR (CC: sample from contaminated cell culture; PC: pure culture of $R$. insidiosa; $\mathrm{H}_{2} \mathrm{O}$ : water control). (C) Gram stain of $R$. insidiosa pure culture originating from the cell culture visualized with a $100 \times$ objective (scale bar: $5 \mu \mathrm{m}$ ). (D) Image of the API ${ }^{\circledR} 20 \mathrm{NE}$ test strip $48 \mathrm{~h}$ after inoculation. (E) Phylogenetic tree based on the core genome (378 genes) of all complete genomes of Ralstonia spp. found in the Refseq database. The framed tree is based on the core genome (3497 genes) of complete and draft genomes of R. insidiosa strains.

\subsection{Antibiotic Susceptibility Profile of R. insidiosa}

Since the contaminant could not be eradicated with antibiotics commonly used in a biomolecular laboratory (penicillin/streptomycin, ampicillin, gentamycin), we determined the antibiotic susceptibility profile of the $R$. insidiosa contamination to finally cleanup the hybridoma cells. Interestingly, this strain of $R$. insidiosa was indeed resistant to multiple antibiotics of different classes (Table 1), including carbapenems and gentamicin. The genotypic resistance determinants are summarized in Table S1. Therefore, based on the susceptibility profile, a decontamination attempt with $0.5 \mathrm{mg} / \mathrm{mL}$ ciprofloxacin 
was performed, which successfully eliminated the contamination without affecting hybridoma cell growth or antibody production.

Table 1. Antibiotic susceptibility profile of the R. insidiosa isolate.

\begin{tabular}{ccc}
\hline Antibiotic Class & Antibiotic & $\begin{array}{c}\text { MIC (Minimal Inhibitory } \\
\text { Concentration }[\mu \mathrm{g} / \mathbf{m L}])^{\mathbf{a}}\end{array}$ \\
\hline Ureidopenicillin/beta lactamase inhibitor & Piperacillin/Tazobactam & $\geq 128(\mathrm{R})$ \\
Cephalosporin & Ceftazidim & $32(\mathrm{R})$ \\
Cephalosporin & Cefepim & $16(\mathrm{R})$ \\
Carbapenem & Imipenem & $>32(\mathrm{R})^{\mathrm{b}}$ \\
Carbapenem & Meropenem & $8(\mathrm{I})^{\mathrm{c}}$ \\
Quinolone & Ciprofloxacin & $0.5(\mathrm{~S})$ \\
Quinolone & Levofloxacin & $1(\mathrm{~S})$ \\
Aminoglycoside & Gentamycin & $\geq 16(\mathrm{R})$ \\
\hline
\end{tabular}

(R): Resistant; (I): Intermediate; (S): Sensitive; ${ }^{\text {a }}$ MIC was tested using VITEK ${ }^{\circledR} 2$, interpretation based on EUCAST clinical breakpoints v10.0 for Pseudomonas spp. (Ralstonia spp. were previously classified as Pseudomonas spp. prior to reclassification to the genus Ralstonia. Breakpoints are not available for Ralstonia spp.); ${ }^{\mathrm{b}}$ Antibiotic susceptibility testing was performed by Etest; ${ }^{\mathrm{C}}$ MIC confirmed by E-test $(8 \mu \mathrm{g} / \mathrm{mL})$.

\subsection{Genomic Characteristics of R. insidiosa}

Despite their clinical relevance as opportunistic multidrug-resistant global pathogens [20] and their emergence as causative agents of nosocomial infections [41,43-45], publicly available genome sequences of $R$. insidiosa are rare. Therefore, we sequenced our isolate to perform a phylogenetical comparison to published Ralstonia spp. sequences to investigate the underlying mechanism for the multidrug-resistance. The phylogenetic tree (Figure 2E) shows that our strain clusters closely with $R$. insidiosa, validating the results obtained by PCR and MALDI-TOF MS. Furthermore, a second phylogenetic tree focusing on $R$. insidiosa showed that our strain clusters in a branch distant from the representative genomes (ATCC ${ }^{\circledR} 49129$ ) and is closely related to strains isolated in the International Space Station (ISS) (NCBI Bioproject Accession: PRJNA493516). Despite an MDR phenotype, analysis of the whole genome sequencing (WGS) data did not detect an abundance of antimicrobial resistance (AMR) genes. Only two class D beta-lactamase encoding genes, blaOXA-573 and blaOXA-574, were identified. We did not find other resistance genes for aminoglycosides, which would explain the gentamicin resistance. However, several genes with around $70 \%$ identity to efflux pump systems found in non-fermenting Gram-negative bacteria were identified and may be responsible for the phenotypic resistance to gentamicin (Table S1). However, our R. insidiosa isolate could not hydrolyze meropenem, as indicated by the negative result of the carbapenem inactivation assay (Figure S1), hence the presence of these genes alone could not explain the carbapenem resistance [41]. This observation is consistent with the result of cloning experiments by Fang et al., which did not demonstrate cabapenemase activity for bla OXA-573 and blaOXA-574 [41]. In addition, OXA-573 belongs to the OXA-60 family, which is intrinsically present in R. pickettii and only exhibits hydrolyzing activity for imipenem but not for meropenem [46]. Nevertheless, the annotation of the genome showed that an efflux RND transporter system and multiple multidrug export/resistance genes are present in this strain, which may explain the resistance to carbapenems. However, without a susceptible strain to compare, we were not able to pinpoint the mutation or gene involved in the carbapenem resistance.

\section{Discussion}

Bacterial contaminations represent a ubiquitous danger for cell cultures, especially when multidrug-resistant bacteria are involved. While contaminated cultures are usually discarded, this is not possible for precious cell lines. Here, we presented several lab techniques to identify the contaminant of our unique hybridoma clones and its antibiotic susceptibility profile in order to enable a decontamination of the cell lines. The contaminant was identified as rod-shaped, Gram-negative, non-fermenting bacterium $R$. insidiosa via PCR, 16S rRNA sequencing and MALDI-TOF MS. As experienced before [44], the API ${ }^{\circledR}$ test was not conclusive. The identification of bacteria of the genus Ralstonia on the species 
level can be challenging, and misclassifications are possible. Due to the low discriminatory power and possibly incomplete database entries, biochemical identification tests are not reliable for correct species identification, as demonstrated in our case by the inconclusive API ${ }^{\circledR}$ test. Consistent with the literature, both PCR-based methods and MALDI-TOF MS could correctly identify our R. insidiosa isolate to the species level, while the latter is probably the fastest and most economical identification method [28,47]. Furthermore, whole genome sequencing (WGS) confirms that our strain is related to $R$. insidiosa. However, it clustered outside of the representative branch, which may indicate that our strain belongs to a species phylogenetically between $R$. insidiosa and $R$. pickettii.

Generally, Ralstonia spp. are considered as robust and tenacious organisms, which thrive well in moist environments [21,48]. Bacteria of the genus Ralstonia are commonly associated with contaminations of medical devices, water and even blood culture bottles [20,49-52]. In addition, colonization and infection with these bacteria are encountered in the immunocompromised and patients on mechanical ventilators $[21,28,44]$. Along with $R$. pickettii, $R$. mannitolilytica, and $R$. insidiosa are the most relevant pathogens of the Ralstonia genus and are considered as emerging opportunistic pathogens with increasing clinical relevance [41]. Infections with $R$. insidiosa can range from minor superficial infections to more severe systemic infections, i.e., bacteremia, even in newborns $[28,41,44,45]$.

Initial decontamination attempts with penicillin/streptomycin, the most commonly used antibiotic combination in cell culture experiments, and even gentamicin, failed to successfully eliminate the contaminant. Indeed, trimethoprim-sulfamethoxazole and quinolones have been suggested as one of the best options to treat Ralstonia. infections as suggested by in vitro susceptibility testing of diverse species [51], which have been described as strong biofilm producers [24,53]. The presence of a biofilm on plastic surfaces may provide a protective environment for contaminants and reduces the efficacy of certain antibiotics [54]. In our setup, we managed to successfully eliminate the contaminant by using the quinolone ciprofloxacin, which can penetrate biofilms [55], and ultimately decontaminated the hybridoma cells without affecting their antibody production.

Systematic antibiotic susceptibility data for Ralstonia spp. are scarce. Nevertheless, several studies and case reports suggested that most Ralstonia spp. are susceptible to commonly used antibiotics [51,56,57]. Our $R$. insidiosa isolate exhibited high-level resistance to all beta-lactams including carbapenems (Table 1). The emergence of MDR $R$. insidiosa in clinical isolates was recently reported from a Chinese tertiary hospital and the carbapenem resistance was attributed to the presence of a class D OXA-type beta-lactamase (bla ${ }_{O X A-570}$ ) [41]. In our isolate, we did not find any evidence for the presence of carbapenem-hydrolyzing enzymes, as shown by a negative in vitro carbapenem inactivation assay. WGS identified the presence of antimicrobial resistance (AMR) genes bla OXA-573 and bla OXA-574 in our R. insidiosa isolate and in the ATCC ${ }^{\circledR} 49129$ R. insidiosa type strain, as well as in 9 of the 12 strains listed in the Refseq database. Both AMR genes are similar to the chromosomally encoded inducible imipenem-hydrolyzing class D beta-lactamases, blaOXA-22 and blaOXA-60, which are widespread in $R$. pickettii [46], but these AMR genes cannot explain the meropenem resistance. Due to the lack of large epidemiological and molecular data, it is not known whether blaOXA-573 and blaOXA-574 are intrinsic to $R$. insidiosa. In our isolate, the reduced susceptibility to meropenem may be mediated by other mechanisms, such as drug efflux pumps or porin loss [58]. Genetically, our R. insidiosa strain clusters with other sequenced and publicly available $R$. insidiosa isolates. Interestingly, our $R$. insidiosa is closely related (single nucleotide polymorphism $<20 \mathrm{nt}$ over the core genome containing 253628 polymorphic sites) to the unpublished $R$. insidiosa isolates from the International Space Station (ISS) (NCBI Bioproject Accession: PRJNA493516). The average nucleotide identity between our strain and the strains S42, S44, S58, and S59 were 99.97\%, 99.35\%, 99.33\%, and 99.35\%, respectively. However, there is no background information on the ISS $R$. insidiosa isolates, so that it is not possible to draw any conclusions from this observation.

Even though our MDR R. insidiosa strain was not isolated from a clinical sample, cumulating reports on the emergence of multidrug resistance in Ralstonia spp. in the context of human infections raise some concern. Due to the lack of systematic epidemiological and resistance data, it is neither 
possible to estimate the prevalence of AMR genes, nor assess the clinical relevance of their presence. Nonetheless, it appears that AMR genes in Ralstonia spp. may be more widespread than previously anticipated and warrant further investigations.

Supplementary Materials: The following are available online at http:/www.mdpi.com/2076-2607/8/10/1599/s1, Table S1: Antimicrobial resistance genes derived from the draft genome of our Ralstonia insidiosa isolate. Figure S1: Our Ralstonia insidiosa (DKFZ001) isolate did not hydrolyze meropenem (top right) as indicated by the similar zone of inhibition comparable to the carbapenemase-negative multi-susceptible E. coli ATCC ${ }^{\circledR} 25922$ (top left). The positive control (carbapenemase-producing C. amalonaticus KE3510) was able to fully hydrolyze meropenem, resulting in an absence of an inhibition zone (bottom).

Author Contributions: Conceptualization, D.H.; methodology, S.B., D.N., K.S. and D.H.; software, D.N., S.B., K.S. and D.H.; validation, S.B., D.N., K.S. and D.H.; formal analysis, S.B., D.N., K.S. and D.H.; investigation, S.B., D.N., K.S., M.A. and D.H.; resources, D.N., K.S. and D.H.; data curation, D.N., K.S. and D.H.; writing一original draft preparation, S.B., D.N., K.S., M.A. and D.H.; writing-review and editing, S.B., D.N. and D.H.; visualization, S.B. and D.H.; supervision, D.H.; project administration, D.H. All authors have read and agreed to the published version of the manuscript.

Funding: M.A. is funded by the Cooperation Program in Cancer Research of the Deutsches Krebsforschungszentrum (DKFZ) and Israel's Ministry of Science and Technology (MOST), project CA182.

Acknowledgments: We thank Karsten Richter (Central Unit Electron Microscopy, DKFZ) for acquisition of TEM images and Damir Krunic (Light Microscopy Facility, DKFZ) for his kind help. We further gratefully thank Frank Rösl (Division of Viral Transformation Mechanisms, DKFZ) for his continuous support.

Conflicts of Interest: The authors declare no conflict of interest.

\section{References}

1. Buehring, G.C.; Eby, E.A.; Eby, M.J. Cell line cross-contamination: How aware are mammalian cell culturists of the problem and how to monitor it? In Vitro Cell. Dev. Biol. Anim. 2004, 40, 211-215. [CrossRef]

2. Huang, Y.; Liu, Y.; Zheng, C.; Shen, C. Investigation of cross-contamination and misidentification of 278 widely used tumor cell lines. PLoS ONE 2017, 12, e0170384. [CrossRef]

3. Almeida, J.L.; Cole, K.D.; Plant, A.L. Standards for cell line authentication and beyond. PLoS Biol. 2016, 14, e1002476. [CrossRef] [PubMed]

4. Yang, Y.; Weng, W.; Peng, J.; Hong, L.; Yang, L.; Toiyama, Y.; Gao, R.; Liu, M.; Yin, M.; Pan, C.; et al. Fusobacterium nucleatum increases proliferation of colorectal cancer cells and tumor development in mice by activating toll-like receptor 4 signaling to nuclear factor-kappab, and up-regulating expression of microrna-21. Gastroenterology 2017, 152, 851-866. [CrossRef]

5. Motedayyen, H.; Fathi, F.; Fasihi-Ramandi, M.; Sabzghabaee, A.M.; Taheri, R.A. Toll-like receptor 4 activation on human amniotic epithelial cells is a risk factor for pregnancy loss. J. Res. Med. Sci. 2019, 24, 1. [PubMed]

6. Uphoff, C.C.; Drexler, H.G. Detecting mycoplasma contamination in cell cultures by polymerase chain reaction. Methods Mol. Bio. 2011, 731, 93-103.

7. Gray, J.S.; Birmingham, J.M.; Fenton, J.I. Got black swimming dots in your cell culture? Identification of achromobacter as a novel cell culture contaminant. Biologicals 2010, 38, 273-277. [CrossRef]

8. Xu, X.; Lai, Y.; Zhou, W.; Wu, L.; Hua, Z. Quantification of a cell culture contaminant using $16 \mathrm{~s}$ rdna. Biotechnol. Appl. Biochem. 2019, 66, 815-822. [CrossRef] [PubMed]

9. Contamination Problems in 293 T Cell Culture. Any Help? Available online: https://www.researchgate.net/ post/Contamination_problems_in_293_T_cell_culture_Any_help (accessed on 24 September 2020).

10. Why Am I Not Able to Get Rid of Bacterial Contamination in Cell Culture? Available online: https://www. researchgate.net/post/Why_am_I_not_able_to_get_rid_of_Bacterial_contamination_in_cell_culture (accessed on 24 September 2020).

11. Any Idea What This Cell Culture Contamination May Be? Available online: https://www.researchgate.net/ post/Any_idea_what_this_cell_culture_contamination_may_be (accessed on 24 September 2020).

12. How to Remove Bacteria from Cell Culture? Available online: https://www.researchgate.net/post/How_to_ remove_bacteria_from_cell_culture (accessed on 24 September 2020).

13. Floating Cells in Adherent Vero Culture. Available online: http://www.protocol-online.org/forums/topic/ 9373-floating-cells-in-adherent-vero-culture/?pid=30730\#entry30730 (accessed on 24 September 2020). 
14. Hasche, D.; Stephan, S.; Savelyeva, L.; Westermann, F.; Rösl, F.; Vinzón, S.E. Establishment of an immortalized skin keratinocyte cell line derived from the animal model mastomys coucha. PLoS ONE 2016, 11, e0161283. [CrossRef]

15. Holzlöhner, P.; Hanack, K. Generation of murine monoclonal antibodies by hybridoma technology. J. Vis. Exp. 2017, 119, 54832. [CrossRef]

16. Richards, M.J.; Edwards, J.R.; Culver, D.H.; Gaynes, R.P. Nosocomial infections in combined medical-surgical intensive care units in the united states. Infect. Control Hosp. Epidemiol. 2000, 21, 510-515. [CrossRef] [PubMed]

17. MacVane, S.H. Antimicrobial resistance in the intensive care unit: A focus on gram-negative bacterial infections. J. Intensive Care Med. 2017, 32, 25-37. [CrossRef]

18. Zeighami, H.; Valadkhani, F.; Shapouri, R.; Samadi, E.; Haghi, F. Virulence characteristics of multidrug resistant biofilm forming acinetobacter baumannii isolated from intensive care unit patients. BMC Infect. Dis. 2019, 19, 629. [CrossRef] [PubMed]

19. Genin, S. Molecular traits controlling host range and adaptation to plants in ralstonia solanacearum. New Phytol. 2010, 187, 920-928. [CrossRef]

20. Ryan, M.P.; Adley, C.C. Ralstonia spp.: Emerging global opportunistic pathogens. Eur. J. Clin. Microbiol. Infect. Dis. 2014, 33, 291-304. [CrossRef] [PubMed]

21. Waugh, J.B.; Granger, W.M.; Gaggar, A. Incidence, relevance and response for ralsfonia respiratory infections. Clin. Lab. Sci. 2010, 23, 99-106. [CrossRef]

22. Coenye, T.; Vandamme, P.; LiPuma, J.J. Infection by ralstonia species in cystic fibrosis patients: Identification of r. Pickettii and r. Mannitolilytica by polymerase chain reaction. Emerg. Infect. Dis. 2002, 8, 692-696. [CrossRef]

23. Guo, A.L.; Xu, Y.F.; Mowery, J.; Nagy, A.; Bauchan, G.; Nou, X.W. Ralstonia insidiosa induces cell aggregation of listeria monocytogenes. Food Control 2016, 67, 303-309. [CrossRef]

24. Xu, Y.; Nagy, A.; Bauchan, G.R.; Xia, X.; Nou, X. Enhanced biofilm formation in dual-species culture of listeria monocytogenes and ralstonia insidiosa. AIMS Microbiol. 2017, 3, 774-783. [CrossRef]

25. Hasche, D.; Rösl, F. Mastomys species as model systems for infectious diseases. Viruses 2019, 11, 182. [CrossRef]

26. Frickmann, H.; Dekker, D.; Schwarz, N.G.; Hahn, A.; Boahen, K.; Sarpong, N.; Adu-Sarkodie, Y.; Halbgewachs, E.; Marks, F.; von Kalckreuth, V.; et al. 16s rrna gene sequence-based identification of bacteria in automatically incubated blood culture materials from tropical sub-saharan africa. PLoS ONE 2015, 10, e0135923. [CrossRef]

27. Srinivasan, R.; Karaoz, U.; Volegova, M.; MacKichan, J.; Kato-Maeda, M.; Miller, S.; Nadarajan, R.; Brodie, E.L.; Lynch, S.V. Use of $16 \mathrm{~s}$ rrna gene for identification of a broad range of clinically relevant bacterial pathogens. PLoS ONE 2015, 10, e0117617. [CrossRef] [PubMed]

28. Coenye, T.; Goris, J.; De Vos, P.; Vandamme, P.; LiPuma, J.J. Classification of ralstonia pickettii-like isolates from the environment and clinical samples as ralstonia insidiosa sp. Nov. Int. J. Syst. Evol. Microbiol. 2003, 53, 1075-1080. [CrossRef] [PubMed]

29. Coico, R. Gram staining. Curr. Protoc. Microbiol. 2005. [CrossRef]

30. Bizzini, A.; Durussel, C.; Bille, J.; Greub, G.; Prod'hom, G. Performance of matrix-assisted laser desorption ionization-time of flight mass spectrometry for identification of bacterial strains routinely isolated in a clinical microbiology laboratory. J. Clin. Microbiol. 2010, 48, 1549-1554. [CrossRef] [PubMed]

31. Ralston, E.; Palleroni, N.J.; Doudoroff, M. Pseudomonas pickettii, a new species of clinical origin related to pseudomonas solanacearum. Int. J. Syst. Evol. Microbiol. 1973, 23, 15-19. [CrossRef]

32. Pierce, V.M.; Simner, P.J.; Lonsway, D.R.; Roe-Carpenter, D.E.; Johnson, J.K.; Brasso, W.B.; Bobenchik, A.M.; Lockett, Z.C.; Charnot-Katsikas, A.; Ferraro, M.J.; et al. Modified carbapenem inactivation method for phenotypic detection of carbapenemase production among enterobacteriaceae. J. Clin. Microbiol. 2017, 55, 2321-2333. [CrossRef]

33. Kocer, K.; Boutin, S.; Dalpke, A.H.; Heeg, K.; Mutters, N.T.; Nurjadi, D. Comparative genomic analysis reveals a high prevalence of inter-species in vivo transfer of carbapenem-resistance plasmids in patients with haematological malignancies. Clin. Microbiol. Infect. 2020, 26, 780. [CrossRef] 
34. Klein, S.; Hannesen, J.; Zanger, P.; Heeg, K.; Boutin, S.; Nurjadi, D. Entry of panton-valentine leukocidin-positive methicillin-resistant staphylococcus aureus into the hospital: Prevalence and population structure in heidelberg, germany 2015-2018. Sci. Rep. 2020, 10, 13243. [CrossRef]

35. Bankevich, A.; Nurk, S.; Antipov, D.; Gurevich, A.A.; Dvorkin, M.; Kulikov, A.S.; Lesin, V.M.; Nikolenko, S.I.; Pham, S.; Prjibelski, A.D.; et al. Spades: A new genome assembly algorithm and its applications to single-cell sequencing. J. Comput. Biol. 2012, 19, 455-477. [CrossRef]

36. Feldgarden, M.; Brover, V.; Haft, D.H.; Prasad, A.B.; Slotta, D.J.; Tolstoy, I.; Tyson, G.H.; Zhao, S.; Hsu, C.H.; McDermott, P.F.; et al. Validating the amrfinder tool and resistance gene database by using antimicrobial resistance genotype-phenotype correlations in a collection of isolates. Antimicrob. Agents Chemother. 2019, 63, e00483-19. [CrossRef] [PubMed]

37. Jia, B.; Raphenya, A.R.; Alcock, B.; Waglechner, N.; Guo, P.; Tsang, K.K.; Lago, B.A.; Dave, B.M.; Pereira, S.; Sharma, A.N.; et al. Card 2017: Expansion and model-centric curation of the comprehensive antibiotic resistance database. Nucleic Acids Res. 2017, 45, D566-D573. [CrossRef] [PubMed]

38. Gupta, S.K.; Padmanabhan, B.R.; Diene, S.M.; Lopez-Rojas, R.; Kempf, M.; Landraud, L.; Rolain, J.M. Arg-annot, a new bioinformatic tool to discover antibiotic resistance genes in bacterial genomes. Antimicrob. Agents Chemother. 2014, 58, 212-220. [CrossRef] [PubMed]

39. Zankari, E.; Hasman, H.; Cosentino, S.; Vestergaard, M.; Rasmussen, S.; Lund, O.; Aarestrup, F.M.; Larsen, M.V. Identification of acquired antimicrobial resistance genes. J. Antimicrob. Chemother. 2012, 67, 2640-2644. [CrossRef]

40. Croucher, N.J.; Page, A.J.; Connor, T.R.; Delaney, A.J.; Keane, J.A.; Bentley, S.D.; Parkhill, J.; Harris, S.R. Rapid phylogenetic analysis of large samples of recombinant bacterial whole genome sequences using gubbins. Nucleic Acids Res. 2015, 43, e15. [CrossRef] [PubMed]

41. Fang, Q.; Feng, Y.; Feng, P.; Wang, X.; Zong, Z. Nosocomial bloodstream infection and the emerging carbapenem-resistant pathogen ralstonia insidiosa. BMC Infect. Dis. 2019, 19, 334. [CrossRef]

42. Geiss, H.K.; Piotrowski, H.D.; Hingst, V. Evaluation of api 20 ne in routine diagnostics of nonfermenting gram-negative rod-shaped bacteria. Zentralbl. Bakteriol. Mikrobiol. Hyg. A 1985, 259, 35-42. [CrossRef]

43. Parnell, L.A.; Briggs, C.M.; Cao, B.; Delannoy-Bruno, O.; Schrieffer, A.E.; Mysorekar, I.U. Microbial communities in placentas from term normal pregnancy exhibit spatially variable profiles. Sci. Rep. 2017, 7, 11200. [CrossRef]

44. Van der beek, D.; Magerman, K.; Bries, G.; Mewis, A.; Declercq, P.; Peeters, V.; Rummens, J.L.; Raymaekers, M.; Cartuyvels, R. Infection with ralstonia insidiosa in two patients. Clin. Microbiol. Newsl. 2005, 27, 159-161. [CrossRef]

45. Akduman Alaşehir, E.; Öngen İpek, B.; Thomas, D.T.; Sitar, M.E.; Erener Ercan, T. Ralstonia insidiosa neonatal sepsis: A case report and review of the literature. Pediatr. Infect. Dis. J. 2020, 15, 148-151. [CrossRef]

46. Girlich, D.; Naas, T.; Nordmann, P. Oxa-60, a chromosomal, inducible, and imipenem-hydrolyzing class d beta-lactamase from ralstonia pickettii. Antimicrob. Agents Chemother. 2004, 48, 4217-4225. [CrossRef]

47. Degand, N.; Carbonnelle, E.; Dauphin, B.; Beretti, J.L.; Le Bourgeois, M.; Sermet-Gaudelus, I.; Segonds, C.; Berche, P.; Nassif, X.; Ferroni, A. Matrix-assisted laser desorption ionization-time of flight mass spectrometry for identification of nonfermenting gram-negative bacilli isolated from cystic fibrosis patients. J. Clin. Microbiol. 2008, 46, 3361-3367. [CrossRef] [PubMed]

48. Verschraegen, G.; Claeys, G.; Meeus, G.; Delanghe, M. Pseudomonas pickettii as a cause of pseudobacteremia. J. Clin. Microbiol. 1985, 21, 278-279. [CrossRef] [PubMed]

49. Boutros, N.; Gonullu, N.; Casetta, A.; Guibert, M.; Ingrand, D.; Lebrun, L. Ralstonia pickettii traced in blood culture bottles. J. Clin. Microbiol. 2002, 40, 2666-2667. [CrossRef]

50. Labarca, J.A.; Trick, W.E.; Peterson, C.L.; Carson, L.A.; Holt, S.C.; Arduino, M.J.; Meylan, M.; Mascola, L.; Jarvis, W.R. A multistate nosocomial outbreak of ralstonia pickettii colonization associated with an intrinsically contaminated respiratory care solution. Clin. Infect. Dis. 1999, 29, 1281-1286. [CrossRef]

51. Ryan, M.P.; Adley, C.C. The antibiotic susceptibility of water-based bacteria ralstonia pickettii and ralstonia insidiosa. J. Med. Microbiol. 2013, 62, 1025-1031. [CrossRef] [PubMed]

52. Ryan, M.P.; Pembroke, J.T.; Adley, C.C. Genotypic and phenotypic diversity of ralstonia pickettii and ralstonia insidiosa isolates from clinical and environmental sources including high-purity water. Diversity in ralstonia pickettii. BMC Microbiol. 2011, 11, 194. [CrossRef] [PubMed] 
53. Adley, C.; Ryan, M.; Pembroke, J.; Saieb, F.M. Ralstonia pickettii: Biofilm formation in high-purity water. In Biofilms: Persistence and Ubiquity; Biofilm Club: Powys, UK, 2005; pp. 261-271.

54. Hoiby, N.; Bjarnsholt, T.; Givskov, M.; Molin, S.; Ciofu, O. Antibiotic resistance of bacterial biofilms. Int. J. Antimicrob. Agents 2010, 35, 322-332. [CrossRef]

55. Walters, M.C., III; Roe, F.; Bugnicourt, A.; Franklin, M.J.; Stewart, P.S. Contributions of antibiotic penetration, oxygen limitation, and low metabolic activity to tolerance of pseudomonas aeruginosa biofilms to ciprofloxacin and tobramycin. Antimicrob. Agents Chemother. 2003, 47, 317-323. [CrossRef]

56. Nasir, N.; Sayeed, M.A.; Jamil, B. Ralstonia pickettii bacteremia: An emerging infection in a tertiary care hospital setting. Cureus 2019, 11, e5084. [CrossRef]

57. Sharma, D.; Sharma, P.; Soni, P.; Gupta, B. Ralstonia picketti neonatal sepsis: A case report. BMC Res. Notes 2017, 10, 28. [CrossRef]

58. Chalhoub, H.; Saenz, Y.; Rodriguez-Villalobos, H.; Denis, O.; Kahl, B.C.; Tulkens, P.M.; Van Bambeke, F. High-level resistance to meropenem in clinical isolates of pseudomonas aeruginosa in the absence of carbapenemases: Role of active efflux and porin alterations. Int. J. Antimicrob. Agents 2016, 48, 740-743. [CrossRef] [PubMed]

Publisher's Note: MDPI stays neutral with regard to jurisdictional claims in published maps and institutional affiliations.

(C) 2020 by the authors. Licensee MDPI, Basel, Switzerland. This article is an open access article distributed under the terms and conditions of the Creative Commons Attribution (CC BY) license (http://creativecommons.org/licenses/by/4.0/). 